We try to publish authors' responses in the same edition with readers' comments. Time constraints might prevent this in some cases. The problem is compounded in a bimonthly journal where continuity of comment and redress are difficult to achieve. When the redress appears 2 months after the comment, 4 months will have passed since the article was published. Therefore, we would suggest to our readers that their correspondence about published papers be submitted as soon as possible after the article appears.

\section{Impact of Religious Attendance on Life Expectancy}

To the Editor: We read with great interest the recent article by Hall, "Religious Attendance: More Cost-effective than Lipitor?" regarding the real-world, practical significance of regular religious attendance on life expectancy. ${ }^{1}$ Evidence is steadily accumulating regarding the associations between a wide variety of religious or spiritual factors and both mental and physical health outcomes and has been systematically reviewed by many others. ${ }^{2-5}$ Whereas we applaud the author's contribution to knowledge concerning the impact of religious attendance on life expectancy, his conclusions regarding the inappropriateness of religious attendance as a therapeutic intervention may be worthy of additional discussion because others have come to different conclusions. ${ }^{6,7}$

Dr. Hall mentions 5 reasons why religious attendance should be viewed as an inert predictor of health (like nationality) rather than as a potential intervention. First, he states plainly: "religious attendance is not a therapy. . . ." Of course in the absence of a compelling rationale for the assertion, this statement is begging the question-it assumes that the answer to the debate has already been decided in favor of his position. Rather, it is precisely the appropriateness of religious attendance as therapy that is in question. Further, we would argue that in many ways, therapy is precisely what religion is for many people. In a world that can at times be overwhelmingly painful, many pursue religious knowledge and activities as a way to cope and make sense of it all. Others seek healing from medical conditions through faith healers or spiritualists, and many more ask for prayer from clergy and fellow members of their religious communities. In the view of all these people, religion does appear to be at least partly therapeutic.

Second, Dr Hall supports his view that religious attendance should not be considered as a medical intervention because "... [T] here is no evidence that changing attendance causes a change in health outcomes." This is a valid observation, and the question of whether increased attendance for the sake of better health actually results in improved health has yet to be determined. However, lack of proof of an effect should not be wrongly interpreted as proof that there is no effect. To evaluate the health effects of a change in religious behav- iors, prospective research would need to be done. The ideal approach of this research would be a randomized intervention trial-something that will never occur if researchers (and funders) take the a priori position that religious activities can never be used as a health-promoting intervention.

The third reason cited for not promoting religious attendance as a therapeutic (or health-promoting) intervention is: "from a theological perspective, such instrumental use of religion is idolatrous." To us, this argument seems to fail on 2 accounts. First, it is not the place of the medical community to determine what is or is not idolatrous or to work toward reducing the amount of idolatry practiced by our patients. Rather, it is incumbent on us to provide treatment and information to help individuals improve their health. Second, there are many instances in the Christian Bible in which people came to Jesus specifically for healing. In almost all these cases, these people received the healing they sought, and rather than rebuking them for their self-interest, Jesus often praised them for their displays of faith. So from the Christian perspective at least, it is debatable that seeking Christ for the purpose of physical healing must necessarily be considered idolatrous.

Fourth, Dr Hall states: “. . . [I]t is not at all clear that "instrumental faith" is sufficiently genuine to accrue the observed reduction in mortality." Again, while this observation appears to be true, it does not necessarily mean that "instrumental faith" is not efficacious; only that more study is needed to answer the question.

Finally, he refers to "the ethical quagmire engendered by any medical recommendation to attend religious services." It is true that there are many ethical questions to be addressed when it comes to physician recommendations regarding religious or spiritual participation or interventions. Considerations such as patient autonomy, physician respect for diversity, and avoidance of offending a patient or creating barriers in the physicianpatient relationship are vital. However, the fact that a topic is ethically difficult need not preclude its discussion in the clinical environment. If that were the case, discussions about abortion, end of life concerns, domestic violence, alcohol and drug abuse, and many other issues would be taboo for the physician. Obviously, when controversial issues impact a patient's health, it is incumbent on the physician to address them with his or her patients, even if the patient's choices are ultimately different from those the physician would prefer or recommend.

In short, research increasingly demonstrates that religious or spiritual behaviors and beliefs are associated with real, measurable, and clinically significant impacts on people's health. Most patients desire to be offered basic spiritual care by their clinicians and censure our 
professions for ignoring their spiritual needs. In addition, professional associations and educational institutions are beginning to provide learners and clinicians information on how to incorporate spirituality and practice. Furthermore, anecdotal evidence indicates that clinicians having received training in providing spiritual or religious interventions in clinical care find it immediately helpful and do apply it to their practice without self-reported evidence of harm. ${ }^{8}$

Therefore, the medical community has an obligation to take the observed relationships seriously and to carefully consider their implications for clinical practice and public health. Our view of the evidence to date is that trained or experienced clinicians should encourage positive spiritual interventions to interested patients (easily determined with any of several simple spiritual assessments) and that there is no evidence that such interventions are, in general, harmful.

Further, unless or until there is evidence of harm from a clinician's provision of either basic spiritual care or a spiritually sensitive practice, interested clinicians and systems should learn to assess their patients' spiritual health and to provide indicated and desired spiritual intervention. Clinicians and health care systems should not, without compelling data to the contrary, deprive their patients of the spiritual support and comfort on which their hope, health, and well-being may hinge.

The possibility of integrating religious/spiritual interventions into medical practice should not be dismissed without a thorough and open discussion about all the issues involved, and without more rigorous research about the potential benefits and/or harms of such interventions.

Joshua R. Mann University of South Carolina School of Medicine, Columbia Walter Larimore University of Colorado Health Sciences Center, Denver

\section{References}

1. Hall DE. Religious attendance: more cost-effective than lipitor? J Am Board Fam Med 2006;19:103-9.

2. Hollins S. Spirituality and religion: exploring the relationship. Nurs Manag (Harrow) 2005;12:22-6.

3. Puchalski C. Spirituality in health: the role of spirituality in critical care. Crit Care Clin 2004;20:487-504.

4. Larson DB, Larson SS, Koenig HG. Mortality and religion/ spirituality: a brief review of the research. Ann Pharmacother 2002;36:1090-8.

5. McCullough ME, Hoyt WT, Larson DB, Koenig HG, Thoresen C. Religious involvement and mortality: a metaanalytic review. Health Psychol 2000;19:211-22.

6. Larimore WL, Parker M, Crowther M. Should clinicians incorporate positive spirituality into their practices? What does the evidence say [review]? Ann Behav Med 2002;24: $69-73$.

7. Larimore WL. Providing basic spiritual care for patients: should it be the exclusive domain of pastoral professionals? Am Fam Physician 2001;63:36, 38-40.
8. Larimore WL, Parker M, Crowther M. Should clinicians incorporate positive spirituality into their practices? What does the evidence say [review]? Ann Behav Med 2002;24: 69-73.

\section{Religious Attendance: More Cost-Effective Than Lipitor?}

To the Editor: The title of this piece is unnecessarily provocative and inappropriate for a scientific medical journal. The study is not, as the author actually acknowledges, a proper econometric analysis. The title is not only deceptive in this regard, but it also suggests - which the author himself disavows - that religious attendance could potentially substitute for cholesterol-lowering drugs or other medical interventions.

The study mentions, but does not address as directly and prominently as it should, the importance of confounding: the idea that people who attend religious services regularly may also be more likely to do other things that benefit their health, such as get regular exercise, eat well, enjoy social support, see doctors, and adhere to medications. Alternatively, healthier people may be more likely than those who are less healthy to attend religious services on a regular basis. Nothing more than a quick nod to these possibilities-which, prima facie, have a more directly causal relationship to health-encourages the interpretation, especially by unsophisticated readers, that religious belief or attendance at religious services is itself responsible for health benefits.

A study such as this should, but does not, present a plausible scientific (read: mechanistic) hypothesis as to why religious attendance, per se, has positive health effects. If confounding variables are more important, then these should be the focus of further research. Simply reporting an association (the veracity of which I do not doubt) and then calling for "further research" is trivial and unworthy of publication in this journal.

Ultimately, I am concerned that this kind of "research" is part of a larger, troubling trend in American society to bring religion closer to politics and to enhance the "scientific credibility" of concepts such as Intelligent Design and the healing power of prayer at a distance (recently discredited in a large clinical trial, by the way). Certainly, religious beliefs are valuable to those who hold them, but scientific studies of the potential health benefits of religion need to go beyond the mere reporting of associations.

I believe your decision to publish this article, and to publish it under the title you did, was regrettable.

Tom Denberg, MD, PhD

Assistant Professor of Medicine,

Division of General Internal Medicine

University of Colorado Health Sciences Center, Denver

\section{Reference}

1. Hall DE. Religious attendance: more cost-effective than lipitor? 2006;19:103-9. 